\title{
DEEP LEVEL TRANSIENT SPECTROSCOPY MEASUREMENTS OF AN ACCEPTOR-LIKE STATE OF METASTABLE EL2 IN GaAs AND GaAsP*
}

\author{
A. Babinśsi, A. Wysmolek ANd T. Seupiński \\ Institute of Experimental Physics, Warsaw University \\ Hoża 69, 00-681 Warszawa, Poland
}

\begin{abstract}
The results of deep level transient spectroscopy measurements of an acceptor-like state of metastable EL2 in $\mathrm{GaAs}$ and $\mathrm{GaAs}_{0.97} \mathrm{P}_{0.03}$ are presented. The uniaxial stress in GaAs was applied in order to find the deep level transient spectroscopy signal. It was found that the deep level transient spectroscopy signal depended on the stress direction. In $\mathrm{GaAs}_{0.97} \mathrm{P}_{0.03}$ the deep level transient spectroscopy peak related to an acceptor-like state of metastable EL2 was observed without external stress.
\end{abstract}

PACS numbers: 71.55.Eq

\section{Introduction}

It is well known that the EL2 defect in the metastable configuration has an acceptor-like state (EL2*(0/-) $)$, degenerate with the conduction band of GaAs [1]. This level enters the gap under hydrostatic pressure. The trapping of an extra electron causes an increase in the sample resistivity. The deep level transient spectroscopy (DLTS) peak related to this level can be observed in GaAs under hydrostatic pressure as well [1]. The DLTS peak related to the $\left(E L 2^{*(0 /-)}\right)$ level was found in mixed GaAlAs crystals too [2].

We performed the DLTS measurements in GaAs under the uniaxial stress and in $\mathrm{GaAs}_{0.97} \mathrm{P}_{0.03}$ without an external stress in order to find the peak related to the $\left(E L 2^{*(0 /-)}\right)$ level. The measurements were performed by means of the isothermal-frequency DLTS mode [3]. The Au-Schottky diodes and In-ohmic contacts were used.

*This work is supported in part by the grant 204249101 of the Committee for Scientific Research. 


\section{GaAs under uniaxial stress}

The GaAs samples (LEC GaAs $n=3 \times 10^{16} \mathrm{~cm}^{-3}$ ) were X-ray oriented and an uniaxial stress could be applied along [100] and [111] direction.

The uniaxial stresses up to $600 \mathrm{MPa}$ were obtained with a press apparatus attached to the Oxford Instruments CF-1204 cryostat.

After cooling down the sample in the dark, there was no DLTS signal at $T=4.2 \mathrm{~K}$ observed (see Fig. 1). After illumination with the 1.05 micron light

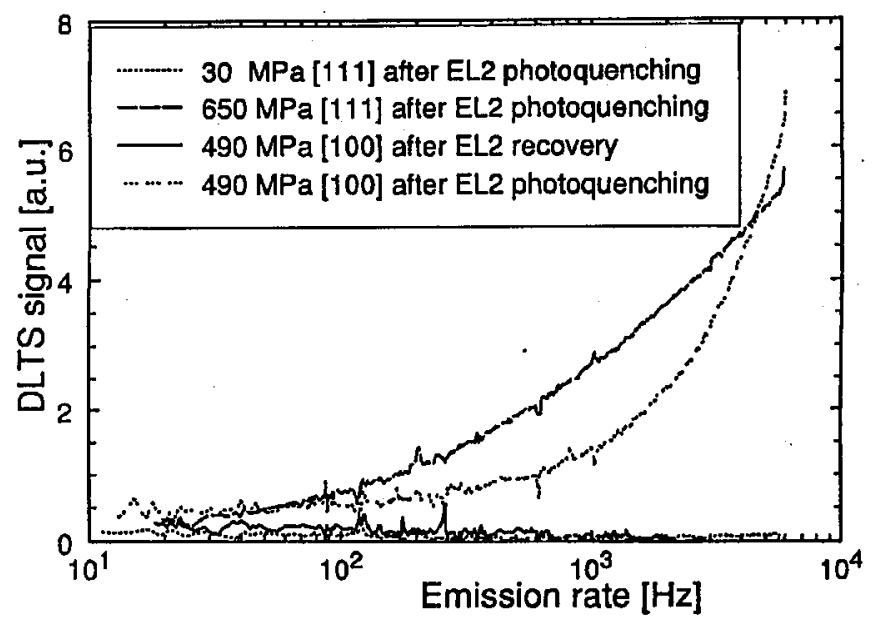

Fig. 1. DLTS signal measured at $T=4.2 \mathrm{~K}$ under [111] and [100] uniaxial stress in GaAs. The sample was cooled down without stress in the dark and illuminated with the 1.05 micron light in order to photoquench EL2. Then the stress was applied. Before illumination and after thermal recovery of EL2 no signal was observed.

and after applying the uniaxial stress the DLTS signal appeared (see Fig. 1). The observed signal increased with the applied stress, and disappeared after heating the sample up to $40-50 \mathrm{~K}$. There was no typical DLTS peak observed, unfortunately. The shape of DLTS signal suggested that the emission rate of investigated level was much higher than $5 \times 10^{3} \mathrm{~Hz}$, the limit of our experimental set-up. It is very likely that such a big emission rate is due to electric field rather than to the thermal activation. Such an effect was observed in GaAs under hydrostatic pressure [1].

Moreover, the shape of the DLTS signal under [111] and [100] stress was different (see Fig. 1). The signal measured under [111] stress seems to be broader than the signal under [100] stress. It is consistent with the recent optical [4] and electrical [5] measurements of the (EL2*(0/-) $)$ level. The $\left(\mathrm{EL} 2^{*(0 /-)}\right)$ level splits into two components under [111] uniaxial stress and does not split under [100] stress [4]. 


\section{3. $\mathrm{GaAs}_{0.97} \mathbf{P}_{0.03}$}

The $\operatorname{GaAs}_{0.97} \mathrm{P}_{0.03}\left(n=4 \div 5 \times 10^{15} \mathrm{~cm}^{-3}\right)$ crystal used in our experiment was grown by LEC technique at the Institute of Experimental Physics. The content of phosphorus was proved by means of near band photoluminescence (PL). The energy gap in investigated material was about $30 \mathrm{meV}$ larger relative to GaAs [6].

The sample was cooled down in the dark and DLTS spectra at several low temperatures $(<30 \mathrm{~K})$ were recorded. No DLTS signal was observed. Then the sample was illuminated with the 1.05 micron light in order to transform EL2 into the metastable configuration. After illumination the DLTS peak at $15-25 \mathrm{~K}$ was created. This peak (see Fig. 2) disappeared after heating up the sample to

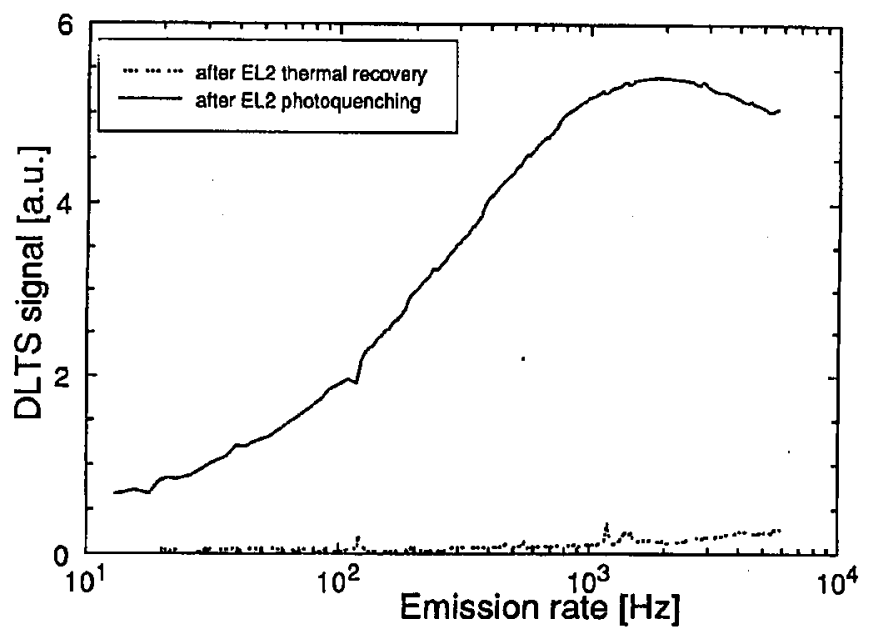

Fig. 2. DLTS signal measured at $T=23 \mathrm{~K}$ in $\mathrm{GaAs}_{0.97} \mathrm{P}_{0.03}$ after EL2 photoquenching (full line) and after EL2 thermal recovery (dashed line).

40-50 K. It was found that electron capture cross-section of investigated level strongly depended on temperature. Taking into account the EL2*(0/-) level energy in GaAs [1] $\left(E_{\mathrm{c}}+0.02 \mathrm{eV}\right)$ and the energy gap broadening due to phosphorus content [6] $(0.03 \mathrm{eV})$, the energy of the investigated level in our mixed crystal can be deduced to be equal aproximately to $E_{\mathrm{c}}-0.01 \mathrm{eV}$. The emission rate activation energy of the investigated level is of the same order of magnitude.

\section{Conclusions}

It was found that the EL2*(0/-) level in GaAs under uniaxial stress can be observed by means of DLTS. The DLTS signal depends on the direction of stress.

In mixed $\mathrm{GaAs}_{0.97} \mathrm{P}_{0.03}$ crystal the EL2*(0/-) level is in the forbidden gap and the DLTS peak related to this level occurs at about $15-25 \mathrm{~K}$. 


\section{References}

[1] M. Baj, P. Dreszer, A. Babiński, Phys. Rev. B 43, 2070 (1991).

[2] D. Stievanard, C. Delerue, G. Bremond, G. Guillot, R. Azoulay, H.J. von Bardeleben, J.C. Bourgoin, J.C. Portal, E. Ranz, Mater. Sci. Forum 83-87, 911 (1992).

[3] G. Ferenczi, J. Boda, T. Pavelka, Phys. Status Solidi A 94, K119 (1986).

[4] P. Trautman, J.M. Baranowski, Phys. Rev. Lett. 69, 664 (1992).

[5] A. Babiński, A. Wysmołek, Acta Phys. Pol. A 82, 908 (1992).

[6] T. Słupiński, G. Nowak, R. Bożek, A. Wysmołek, M. Baj, to be published in $E-M R S$ 1993 Spring Meeting Conference Materials. 